\title{
A PROGRAMAÇÃO TEMPORAL NO CINEMA: A REPRESENTAÇÃO DA ORDEM DOS ACONTECIMENTOS
}

\author{
TEMPORAL PROGRAMMING IN THE CINEMA: \\ THE REPRESENTATION OF THE ORDER OF EVENTS
}

\author{
Odair José Moreira da SILVA ${ }^{1}$ \\ USP - Universidade de São Paulo
}

\begin{abstract}
RESUMO: As possibilidades que o cinema oferece para as análises que envolvem a categoria do tempo no âmbito da enunciação são muitas. Uma delas está notadamente centrada naquilo que a semiótica francesa entende por programação temporal, ou seja, a representação da ordem dos acontecimentos. A história em um filme pode ser contada de diversas maneiras e os acontecimentos podem ser ordenados em decorrência das exigências estabelecidas por uma maneira de contá-los. Partindo dessa premissa, o que se pretende com este trabalho é verificar como o cinema opera com essa particularidade da categoria do tempo e como a programação temporal é representada na diegese dos filmes. Para isso, certos aspectos serão observados aqui como orientadores da representação da ordem dos acontecimentos: a simultaneização, a sucessão e a inversão.
\end{abstract}

PALAVRAS-CHAVE: Semiótica Francesa; Enunciação; Programação Temporal; Cinema.

ABSTRACT: The possibilities that cinema offers for the analysis involving the category of time in the field of enunciation are many. One of them is particularly focused on what the French semiotic means by the temporal programming, i.e., the representation of the order of events. The story in a movie can be told in various ways and events can be ordered as a result of requirements established for a way to count them. Based on that, what I propose in this paper is to check how the cinema operates on this particular category of time and how the timing is represented in the diegesis of the films. For this, certain aspects will be observed here as guidelines for the representation of the order of events: the concurrently, the succession and the reversal.

KEYWORDS: French Semiotics; Enunciation; Temporal Programming; Cinema.

\section{Introdução}

A programação temporal irá operar com a representação dos fatos distintos, ou seja, das ações narrativas, que ocorrem na diegese fílmica sob diversos aspectos. A diegese pode ser entendida, do ponto de vista genettiano, como aquela que visa a "designar o universo espacial-temporal no qual a se desenrola a história” (REIS; LOPES, 2002, p. 26); desse

\footnotetext{
${ }^{1}$ Mestre e doutorando em Semiótica e Linguística Geral pelo Departamento de Linguística da Faculdade de Filosofia, Letras e Ciências Humanas da Universidade de São Paulo / CNPq.
} 
modo, ela indica o aspecto narrativo do discurso cinematográfico. Étienne Souriau, paralelo à concepção de Gerard Genette sobre a diegese, utiliza o termo no âmbito do discurso cinematográfico. Para o autor "os fatos diegéticos" são aqueles "relativos à história representada na tela, relativos à apresentação em projeção diante dos espectadores. É diegético tudo o que supostamente se passa conforme a ficção que o filme apresenta, tudo o que essa ficção implicaria se fosse supostamente verdadeira" (AUMONT; MARIE, 2003, p. 77). É com base nessa concepção de Souriau que operaremos com a diegese fílmica.

Com o recurso da programação temporal, os fatos podem ser operados simultaneamente, sucessivamente ou de maneira invertida. Disso resulta que as ações narrativas podem ser representadas em uma concomitância, em uma sucessão ou em uma discordância em relação à cronologia dos acontecimentos.

Antes, porém, de esmiuçar como fatos distintos são representados, torna-se necessário expor o que a semiótica francesa define como programação temporal.

Segundo Greimas e Courtés (2008), a programação temporal tem como principal característica a conversão do eixo das pressuposições em eixo das consecuções. O eixo das pressuposições representa a ordem lógica do encadeamento dos estados e transformações da narrativa, ou seja, dos programas narrativos, que são entendidos como um enunciado de fazer que rege um enunciado de estado. Dessa forma, a conversão desse eixo no eixo das consecuções dá lugar à exposição temporal e pseudo-causal das ações narradas. Diana Luz Pessoa de Barros (1988) dirá que a programação temporal estabelece uma cronologia a partir da realização da sintagmatização dos tempos e que a ordem temporal irá substituir a ordem lógica. Por esse processo, teremos a transformação da organização narrativa em história. Tal processo pode ser verificado em qualquer tipo de texto.

Um exemplo disso pode ser encontrado em Deus e o diabo na terra do sol (2006), de Glauber Rocha. A ação central desse filme (a busca do cangaceiro Corisco por Antonio das Mortes) requer a organização de programas principais e secundários para sua realização. Pode-se, pois, dizer que a ordem narrativa irá consistir em, partindo do programa final, que é a captura e a morte de Corisco, ir, mediante uma cadeia de pressuposições lógicas, de um programa a outro, até o estado inicial que se caracteriza pela intenção de capturar Corisco e de acabar com a existência do mal perpetrado por ele. Greimas e Courtés (2008, p. 391) irão dizer que a programação temporal "tem como efeito inverter essa ordem e substituíla por uma ordem 'cronológica' que dispõe os PN de uso ${ }^{2}$ em consecução temporal". A programação temporal é a organização cronológica do discurso.

No filme que tomamos como exemplo, a busca de Corisco empreendida por Antonio das Mortes é realizada mediante uma organização de eventos que dá à narrativa uma ordem cronológica, em que Antonio das Mortes, após várias andanças e aventuras pelo sertão nordestino, encontra Corisco e mata-o, dando por encerrada sua missão. A programação temporal organizou os tempos da busca e do encontro; organizou os tempos da vida e da morte; organizou os tempos de Antonio das Mortes e de Corisco. Em suma, o encontro de ambos encerra os fatos iniciados a partir do estado inicial de Antonio das Mortes, que passam por sua luta e busca incessantes para acabar com o mal representado pelo cangaceiro.

José Luiz Fiorin observa que a programação temporal estabelece relações entre os acontecimentos e a temporalização do enunciado. Segundo o autor

Os acontecimentos, que não têm temporalização, podem ser apresentados sucessivamente ou simultaneamente. A sucessão pode respeitar a relação de implicação lógica ou não, pode desenvolver-se de maneira

\footnotetext{
${ }^{2}$ Programas secundários em relação ao programa principal (PN de base).
} 
progressiva em seu encadeamento de causa e consequência ou não. (FIORIN, 1996, p. 242).

O cinema, na representação dos acontecimentos, trabalha também dessa maneira. Um enunciado fílmico é uma rede de acontecimentos que está à disposição das várias possibilidades de construção da estrutura temporal da narrativa. A construção dessa estrutura temporal ora trabalha com o plano do conteúdo (relacionado com a programação temporal), ora com o plano da expressão (relacionado com a programação textual e, por sua vez, com a duraçãa). Com relação à programação textual no cinema, é preciso estabelecer, sucintamente, uma distinção entre esta e a programação temporal. Notam Greimas e Courtés (2008, p. 392) que

a programação temporal, que resulta no estabelecimento de uma cronologia, não deve ser confundida com a programação textual [...] que o enunciador efetua obedecendo às coerções e aproveitando as liberdades devidas à natureza linear (temporal ou espacial) do texto.

Diana Luz Pessoa de Barros (1988, p. 89-90) observa que a programação temporal, que realiza a sintagmatização dos tempos e estabelece uma cronologia, deve ser distinguida da programação textual, em que o sujeito da enunciação "tem, por exemplo, liberdade para reorganizar a cronologia". Fiorin (1996, p. 234) reserva à programação temporal "somente àquilo que é manifestado pelo tempo crônico ou que diz respeito à sucessividade ou simultaneidade dos acontecimentos". No que se refere à programação textual, o autor de As astúcias da enunciação tem uma concepção um pouco mais restrita. Fiorin (1996, p. 248) considera que pertencem ao nível discursivo "toda organização temporal marcada por meio de formas gramaticais e do estabelecimento de relações no interior do texto". Com relação ao nível textual, pertencem a este somente aqueles procedimentos que têm por objetivo, de alguma forma, obedecer às coerções da linearidade ou evitá-las. Fiorin (1996, p. 248) observa que a programação textual "está relacionada tão-somente ao plano da expressão. Já simultaneidades, anterioridades e posterioridades são relações do plano do conteúdo e, por conseguinte, pertencem ao nível do discurso". Silva (2004, p. 157), toma como ponto de partida a concepção de Fiorin, restringindo-a ainda mais. A programação textual diz respeito à manifestação da duração no texto. Todos os acontecimentos discursivizados apresentam uma duração e ela pode ser manifestada, no texto fílmico, de três maneiras:

a) identidade: a duração na manifestação é idêntica à duração do acontecimento discursivizado;

b) expansão: a duração na manifestação é maior do que a duração do acontecimento discursivizado;

c) condensação: a duração na manifestação é menor do que o acontecimento discursivizado.

Ao voltar os olhos para a programação temporal, nosso foco principal aqui, notamos que a história, em um filme, pode ser contada de diversas maneiras e que os acontecimentos podem ser ordenados em decorrência das exigências estabelecidas por uma maneira de contá-los. As maneiras de ordená-los são a simultaneização, a sucessão e a inversão. Analisemos cada uma delas. 


\section{Concomitância dos fatos distintos (a simultaneização dos acontecimentos)}

A simultaneização é a indicação de que diferentes ações estão ocorrendo concomitantemente.

A simultaneidade dos acontecimentos no cinema, assim como na língua, pode ser indicada, de modo geral, sob duas formas: uma explícita e outra implícita. A marcação explícita de ações simultâneas ocorre quando um processo, como a divisão da tela, por exemplo, marca a simultaneidade. A implícita acontece quando, por exemplo, por meio de cortes secos (entendidos aqui como a passagem de um plano a outro, de uma sequência a outra, por uma simples colagem, onde não há a marcação da mudança, seja por um efeito de ritmo ou por uma trucagem, em que o único objetivo é a instauração de outro espaço-tempo narrativo) ou legendas (que também indicam mudança de uma sequência primeira para outra, instaurando também outro espaço-tempo), há um vaivém de uma ação para outra ou passa-se de uma para outra. Chamamos a primeira explícita, porque nela se mostram, ao mesmo tempo, acontecimentos simultâneos que ocorrem em espaços distintos. Chamamos a outra implícita, porque os fatos simultâneos são mostrados sucessivamente e processos, como legendas ou cortes, criam uma ilusão de simultaneidade.

Em Monty Python em busca do cálice sagrado (2002), de Terry Gilliam e Terry Jones, temos um exemplo da indicação implícita da simultaneidade dos acontecimentos. O rei Arthur, ordenado por Deus, convoca alguns cavaleiros para ajudá-lo a procurar o famoso cálice que Jesus Cristo usou na Última Ceia.

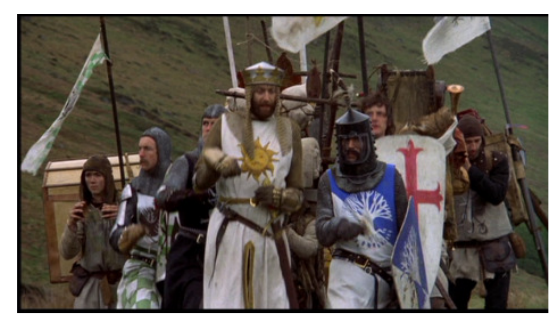

Fotograma 1: Rei Arthur e o grupo dos cavaleiros reunidos

O grupo dos cavaleiros separa-se e com isso temos quatro contos distintos: o conto de sir Robin, o de sir Galahad, o de rei Arthur com sir Bedevere e, finalmente, o de sir Lancelot. Sir Robin vai para o norte, para a floresta de Ewig, lugar sombrio, onde encontra o cavaleiro de três cabeças. Com a indecisão do cavaleiro em matá-lo ou não, sir Robin foge como um covarde. Sir Galahad, o puro, após atravessar uma floresta em meio a uma tempestade, chega a um castelo conhecido como Castelo Antraz, habitado por várias donzelas, que querem seduzi-lo e desviá-lo de seu caminho. Após resistir bravamente às tentações, consegue fugir do castelo com a ajuda de alguns cavaleiros que aparecem para auxiliá-lo. Sir Bedevere e o rei Arthur conversam com um bruxo que dá pistas estranhas aos dois. No meio de uma floresta assustadora encontram os temíveis cavaleiros que dizem "NI". Após um acordo, o rei Arthur e sir Bedevere partem à procura daquilo que os cavaleiros exigiram: um arbusto. Após receber uma misteriosa mensagem, sir Lancelot chega a um castelo para salvar uma vítima de um casamento forçado. Após lutar com os guardas e com todo mundo que vê pela frente, o bravo cavaleiro decepciona-se com o que encontra: a carta era de um príncipe efeminado, que queria apenas cantar. A narrativa toma seu andamento central novamente quando o rei Arthur e sir Bedevere encontram sir Robin e juntos unem-se a sir Galahad e sir 
Lancelot. $\mathrm{O}$ grupo refeito, Arthur e os cavaleiros dão prosseguimento à jornada em busca do cálice sagrado.

As aventuras, embora possuam outros espaços e outros tempos, acontecem concomitantemente. No entanto, essa simultaneidade de cada fato é ordenada de forma que cada cavaleiro vai realizando uma aventura por vez. Desse modo, o enunciado fílmico irá apresentar essa simultaneidade de forma única, ao passo que o espectador irá acompanhá-las uma de cada vez, sem que para isso o efeito de sentido de uma temporalidade una que rege o enunciado fílmico seja quebrado pelas outras temporalidades dos cavaleiros. A temporalidade maior é suspensa pelas menores. Aliás, essas micro-temporalidades, se é que podemos denominá-las assim, são partes que complementam um todo temporal, representado na diegese do filme. E isso pode ser compreendido quando uma legenda introduz o nome dos cavaleiros e cada um deles terá um episódio novo e, ao mesmo tempo, simultâneo aos outros: a partir das orientações do rei Arthur cada cavaleiro sai em busca de pistas que possam indicar o verdadeiro caminho para encontrar o cálice sagrado. Sir Robin, sir Galahad, rei Artur com sir Bedevere e sir Lancelot partem rumo às suas aventuras na busca do Santo Graal.
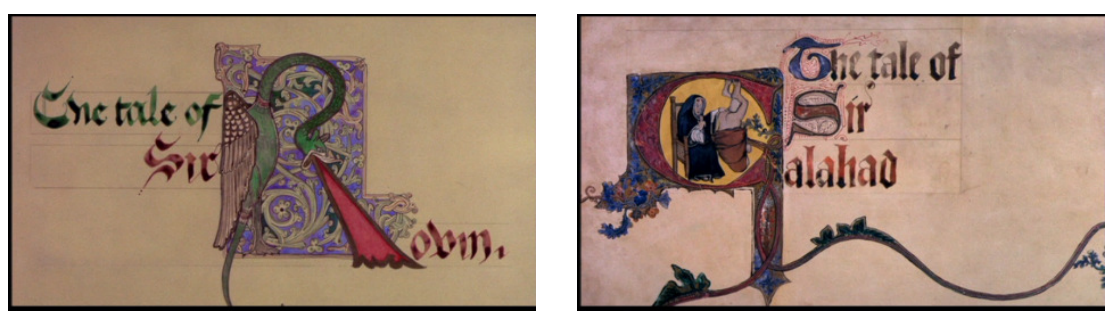

Fotogramas 2 e 3: As apresentações de sir Robin e sir Galahad

No momento em que a legenda situa-nos no início de cada episódio dos cavaleiros, a temporalidade da narrativa que estava sendo contada é suspensa para que outra temporalidade, no caso a da primeira ação e, logo depois, as posteriores a ela, possa ser narrada e assim sucessivamente. Essa suspensão também acontece no caso dos episódios. Cada um deles possui a sua temporalidade particular, com algo parecido com começo, desenvolvimento e fim. A suspensão ocorre no final do episódio para que o seguinte prossiga com sua temporalidade. É preciso lembrar que a simultaneidade desses espaços-tempos narrativos somente ganha corpo a partir da divisão dos grupos que têm por objetivo realizar as ordens do rei Arthur. Cada legenda indica uma espécie de desencadeamento de outra temporalidade e de sua manifestação: é como se voltássemos ao instante da divisão dos grupos feita pelo rei Arthur e, a partir desse momento, cada episódio desenvolve, com sua temporalidade particular, a progressão sucessiva até o início do seguinte, e assim por diante. Os episódios são simultâneos, mas aparecem na tela individualmente.

\begin{tabular}{|c|c|c|}
\hline Temporalidade em curso normal & $\begin{array}{c}\text { Temporalidade cindida e } \\
\text { distribuída entre cada } \\
\text { personagem }\end{array}$ & $\begin{array}{c}\text { Fusão das temporalidades } \\
\text { individuais e retomada da } \\
\text { temporalidade normal da narrativa }\end{array}$ \\
\hline \multirow{2}{*}{$\begin{array}{c}\text { Rei Arthur e o momento da } \\
\text { divisão dos grupos de cavaleiros } \\
\text { que saem em busca de indícios que }\end{array}$} & $\begin{array}{c}\mathbf{1}^{\circ} \text { conto: Sir Robin - e o tempo } \\
\text { transcorrido de sua aventura. }\end{array}$ & \\
\cline { 2 - 2 } & $\begin{array}{c}\mid c \\
\text { conto: Sir Galahad - e o tempo } \\
\text { transcorrido de sua aventura. }\end{array}$ & \multirow{2}{*}{ Momento da reunião do grupo } \\
\hline
\end{tabular}




\begin{tabular}{|c|c|c|}
\hline $\begin{array}{c}\text { levem ao Santo Graal - } \\
\text { Temporalidade transcorrida } \\
\text { normalmente até o momento da } \\
\text { divisão dos grupos. }\end{array}$ & $\begin{array}{c}\mathbf{3}^{\circ} \text { conto: Rei Arthur e sir Bedevere } \\
\text { - e o tempo transcorrido de sua } \\
\text { aventura. }\end{array}$ & novamente \\
\cline { 2 - 3 } & $\begin{array}{c}\mathbf{4}^{\circ} \text { conto: Sir Lancelot - e o tempo } \\
\text { transcorrido de sua aventura. }\end{array}$ & \\
\hline
\end{tabular}

Tabela 1: A divisão em episódios da narrativa de Monty Python em busca do cálice sagrado

Pelo esquema exposto, podemos perceber que a diegese fílmica transcorre normalmente até o momento em que o rei Arthur divide os grupos. Cada cavaleiro tem uma aventura, como já vimos mais acima; tem também uma temporalidade particular, que se encerra quando sua aventura finda e inicia-se a aventura de um outro cavaleiro. Quando termina a narração das aventuras simultâneas, ocorre a reunião dos grupos e, a partir daí, a sucessão dos acontecimentos da diegese fílmica desenrola-se até seu final. O mesmo processo dessa marcação da simultaneidade dos acontecimentos pode ser visto nos filmes que compõem a trilogia $O$ Senhor dos anéis - A Sociedade do anel (2001), As Duas torres (2002) e $O$ Retorno do rei (2003), de Peter Jackson. Há uma separação em grupos e cada grupo desenvolve a sua própria temporalidade dos acontecimentos que é simultânea à dos demais.

Em Narc (2002), de Joe Carnahan, temos um caso em que a simultaneidade de fatos distintos é indicada, dessa vez, explicitamente.

Nick Tellis é um policial da divisão de narcóticos do Departamento de Polícia de Detroit. Nick é do tipo de policial que trabalha disfarçado, arriscando a própria vida. Quase morre em uma missão e decide mudar de base de operação. Nick aceita trabalhar em um caso de homicídio ao lado de Henry Oak, um policial linha dura, que não tem a intenção de apenas prender os assassinos de seu parceiro. Uma investigação árdua tem início e os dois policiais partem em busca de pistas que possam ajudar a encontrar os verdadeiros assassinos do parceiro de Henry. Nick e Henry empreendem uma investigação, cada um à sua maneira, pelos submundos de Detroit. Simultaneamente Henry e Nick aventuram-se pelos lugares mais suspeitos possíveis: enquanto o primeiro vai para a região oeste, o outro vai para a região leste. $\mathrm{Na}$ diegese fílmica, uma cena deixa explícita essa simultaneização dos fatos vividos tanto por Nick quanto por Henry: a princípio, a tela é dividida em duas, mostrando em cada parte da divisão as ações simultâneas de Nick e Henry no submundo do crime. Essa exposição das ações divididas em duas partes na tela dura alguns segundos, quando há uma nova cisão e vemos a tela dividida em quatro partes e, em cada uma dessas partes, a progressão das investigações dos dois policiais. Alguns minutos depois as partes juntam-se e a tela volta ao normal.

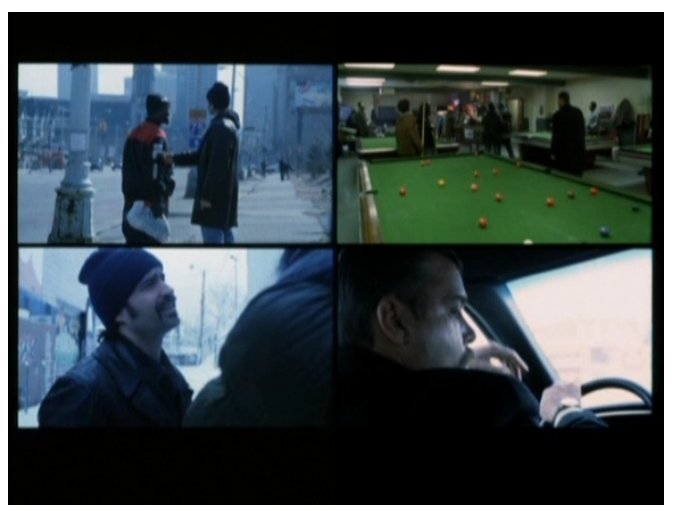

Fotograma 4: a tela dividida em quatro partes indica a ação simultânea de cada policial 
Exemplo semelhante pode ser encontrado no filme A Máquina do tempo (2002), de Simon Wells, em que a cena final apresenta uma curiosa simultaneização dos acontecimentos de forma explícita: a tela é dividida em duas partes e, em cada uma delas, ações simultâneas acontecem em um mesmo espaço, a casa do cientista, mas em épocas diferentes. No passado, o criado do cientista perambula pela casa imaginando onde seu senhor poderia estar; no futuro, em relação ao passado do criado, o cientista, junto com um grupo de novos amigos, espreita uma construção abandonada e reconhece que se trata de sua antiga morada. As duas cenas acontecem simultaneamente, na tela, em um mesmo campo de visão.

Em princípio, pode-se dizer que a narrativa fílmica, que tem como programação temporal a simultaneização (a concomitância dos fatos distintos), apresenta dois modi operandis:

a) o primeiro, implícito, é aquele em que os acontecimentos simultâneos são narrados em sucessão, como proposta de uma temporalidade única que o enunciado apresenta; no entanto, a experiência do espectador é vivenciar cada uma das micro-temporalidades que formam o todo temporal sucessivo. Um dos recursos visuais que o cinema apresenta para marcar essa concomitância das micro-temporalidades, ou melhor, desses outros espaçostempos, pode ser concretizado com os cortes secos e as legendas, por exemplo, que produzem a ideia de simultaneidade, quando suspendem a narrativa principal para inserir outros acontecimentos paralelos que, de certa forma, pertencem à diegese fílmica, formando um todo espaço-temporal. $\mathrm{O}$ que ocorre, nesse caso, é que as temporalidades se alternam, criando, assim, um ritmo alternado na narrativa do filme. $\mathrm{O}$ efeito de sentido que se espera aqui é a compreensão mediata, passiva, do espectador em relação ao desenrolar dos acontecimentos, aumentando o suspense por meio de um retardamento temporal. Em Monty Python em busca do cálice sagrado, por exemplo, esse ritmo alternado tem por mérito apresentar as diversas experiências vividas pelos cavaleiros e o modo como cada um deles reagiu diante de uma situação problemática e, de certa forma, emblemática na consecução e resolução de seus objetivos. O filme ilustra muito bem esse processo, como vimos anteriormente: cada cavaleiro do rei Artur tem a sua própria temporalidade; quando, na tela, acontece a temporalidade de um cavaleiro específico, a diegese fílmica principal é suspensa para que uma outra paralela, em um espaço-tempo diferente, seja contada, e assim sucessivamente, até o retorno do andamento normal da narrativa original.

\begin{tabular}{|c|c|c|c|}
\hline \multicolumn{4}{|c|}{$\begin{array}{c}\text { Progressão em ritmo alternado = Monty Python em busca do cálice sagrado } \\
\text { (Implícita) }\end{array}$} \\
\hline \multicolumn{4}{|c|}{ - Rei Arthur e os cavaleiros Divisão em grupos } \\
\hline$\underset{\nabla}{\text { Sir Robin }}$ & $\underset{\boldsymbol{\nabla}}{\operatorname{Sir} \text { Galahad }}$ & Rei Arthur e sir Bevedere & $\underset{\nabla}{\text { Sir Lancelot }}$ \\
\hline \multicolumn{4}{|c|}{$\begin{array}{l}\text { Parada da progressão sucessiva Temporalidade 1, de Sir Robin, que volta para a Temporalidade 2, de sir } \\
\text { Galahad, que volta para a Temporalidade 3, de Arthur e sir Bevedere, que volta para a Temporalidade 4, de } \\
\text { sir Lancelot }\end{array}$} \\
\hline
\end{tabular}


- União do grupo Progressão contínua e sucessiva.

Tabela 2: Progressão em ritmo alternado

b) O segundo, explícito, é aquele em que a simultaneização é apresentada concomitantemente, ou seja, as temporalidades oriundas de outros espaços-tempos são visíveis ao mesmo tempo por um processo que divide a tela em duas ou mais partes, como é o caso das ações dos dois policiais em Narc e das ações finais em A máquina do tempo. Nesse caso, não se altera o ritmo do desenrolar progressivo da história e o espectador vê as temporalidades distintas acontecerem juntas. Basta ver que os dois policiais de Narc, por exemplo, tiveram suas ações simultâneas explicitadas na tela, dividida, inicialmente, em duas partes, sem que para isso fosse preciso retardar o andamento da diegese fílmica. Podemos falar aqui, nessa explicitação de ações simultâneas, de um ritmo contínuo na progressão da narrativa, que tem por efeito de sentido a compreensão imediata, ativa, por parte do espectador, em relação ao desenrolar dos acontecimentos, pois a falta de um retardamento temporal não instaura o suspense concernente às ações desenvolvidas de imediato por parte de cada personagem em seu espaço-tempo particular.

\begin{tabular}{|c|c|c|c|c|c|}
\hline $\begin{array}{l}\text { Progressão em } \\
\text { ritmo contínuo = }\end{array}$ & \multicolumn{2}{|c|}{$\begin{array}{l}\text { Temporalidade } \\
\text { individual, sem a } \\
\text { divisão da tela }\end{array}$} & \multicolumn{2}{|c|}{$\begin{array}{c}\text { Cisão entre as temporalidades } \\
\text { individuais em favor da } \\
\text { simultaneidade entre as narrativas - } \\
\text { divisão da tela em duas / quatro } \\
\text { partes }\end{array}$} & $\begin{array}{l}\text { União das } \\
\text { temporalidades } \\
\text { individuais }\end{array}$ \\
\hline (Explícita) & Nick & Henry & Nick & Henry & $\begin{array}{c}\text { Progressão contínua e } \\
\text { sucessiva }\end{array}$ \\
\hline
\end{tabular}

Tabela 3: Progressão em ritmo contínuo

\section{Sucessão dos fatos distintos (posteriorização dos acontecimentos)}

A sucessão narrativa que respeita o desenrolar progressivo dos acontecimentos, está relacionada aos momentos de referência da localização temporal dos eventos. Os acontecimentos são temporalizados a partir do momento de referência inicial e são narrados em sucessão.

Fiorin (1996, p. 145) estabelece dois pontos para marcar a singularidade do tempo linguístico: a) seu eixo ordenador e gerador é o momento da enunciação; b) está relacionado à ordenação dos estados e transformações narrados no texto. Disso irá decorrer que existem, na língua, dois sistemas temporais: um enunciativo, que se relaciona diretamente ao momento da enunciação (ME) e o outro enuncivo, este ordenado em função de momentos de referência (MR), pretérito e futuro, instalados no enunciado. No entanto, é preciso considerar que o momento de referência "está relacionado ao momento da enunciação, já que este é o eixo fundamental da ordenação temporal na língua" (FIORIN, 1996, p. 145).

O momento dos acontecimentos (MA), ou seja, dos estados e transformações, por sua vez, é ordenado em relação aos diferentes momentos de referência. Se aplicarmos aos diferentes momentos de referência a categoria topológica concomitância vs nãoconcomitância estaremos fazendo essa ordenação. Disso decorre que os momentos estruturalmente relevantes na constituição do sistema temporal são três: momento da 
enunciação (ME), momento da referência (MR) e momento do acontecimento (MA). Dois eixos são salientados pelo autor de Astúcias da enunciação (1996, p. 147): um primeiro que resulta da aplicação da categoria topológica ao momento da enunciação. A partir dessa aplicação, haverá a criação de três momentos de referência e a distinção de dois sistemas temporais, um enunciativo e outro enuncivo. O sistema temporal enuncivo terá, então, dois subsistemas: um centrado num momento de referência pretérito e o outro, num momento de referência futuro; e outro segundo que decorre da utilização da categoria topológica em relação aos momentos de referência. A partir daí, haverá a distinção de uma relação de simultaneidade, uma de anterioridade e uma de posterioridade.

Quando se projetam no enunciado os tempos do sistema enunciativo temos uma debreagem temporal enunciativa. Os tempos do sistema enuncivo, quando se estabelecem no enunciado, produzem a debreagem enunciva. A debreagem temporal poderá ser de primeiro ou de segundo graus. Quando os tempos estiverem relacionados à voz do narrador, teremos o primeiro caso; quando resultarem de uma delegação de voz operada pelo narrador e, assim, estiverem vinculados ao eu interlocutor, teremos o segundo caso (FIORIN, 1996, p. 147).

Partimos da premissa de que o cinema possui um único tempo: o presente (concomitância). O cinema é a arte do presente, dado que recria os acontecimentos para o espectador. Como bem observou Jean Mitry (1965, p.259), o presente é a testemunha dos acontecimentos passados e futuros. É como se o espectador fosse testemunha da ação no seu fazer-se. Haveria um presente zero, que é o do momento da enunciação. Aplicando-se ao momento da enunciação a categoria topológica da concomitância vs não-concomitância (anterioridade vs posterioridade), teríamos três momentos de referência: um presente, um passado e um futuro. Os acontecimentos seriam concomitantes a cada um desses momentos. Assim, teríamos, no cinema, um sistema de três concomitâncias: uma concomitância do presente, uma concomitância do passado e uma concomitância do futuro.

O presente do presente refere-se ao momento da enunciação; o presente do passado concerne a um marco temporal passado e mostra o presente desse passado; e o presente do futuro situa a ação no futuro e mostra o presente desse futuro. Vejamos cada um deles.

O presente do presente seria uma espécie de recorte da atualidade, em que obtemos, no momento em que se enuncia a narrativa, um simulacro de uma realidade onde um fato qualquer se desenvolve progressivamente. No presente do presente, teríamos aquelas narrativas que situam os acontecimentos em um agora debreado enunciativamente. Em $A$ primeira noite de um homem (1999), de Mike Nichols, um rapaz, que acabara de voltar para casa após graduar-se em uma universidade, tem sua vida virada de cabeça para baixo quando começa a sair com a mãe de sua futura namorada. A ação que está sendo mostrada é o presente na vida do rapaz; a debreagem enunciativa instaura um agora que é o momento presente da personagem em conflito concomitante ao momento da enunciação. A ação de ambos os filmes é localizada numa concomitância a um momento de referência presente, que é concomitante ao momento da enunciação.

O presente do passado pode ser considerado como uma espécie de recorte de outrora em que um momento do passado é marcado e narra-se a concomitância desse passado (por exemplo, um episódio histórico marcante como em A Ponte do Rio Kwai (2000), de David Lean, em que um comandante britânico lidera um grupo de prisioneiros dos japoneses na Birmânia, durante a II Guerra Mundial; submetidos a duro tratamento, eles são induzidos a construir uma ponte que servirá ao inimigo). O presente do passado refere-se à narração de um acontecimento passado concomitante a um marco temporal pretérito. Ao nos 
colocar como espectadores, testemunhamos o presente dos acontecimentos em relação a esse marco. Nessa instauração de um tempo de outrora, temos a concomitância do vivido, não um retorno ao vivido. Essa concomitância nada mais é do que uma testemunha, um receptáculo de lembranças. O momento da enunciação (ME), o presente implícito, de acordo com a proposta de Fiorin (1996), é o lugar a partir do qual esse presente se estabelece.

Por sua vez, o presente do futuro nada mais é do que um recorte do devir, marcando a concomitância do futuro. Em Blade Runner - $O$ caçador de andróides (2006), de Ridley Scott, por exemplo, o homem, no ano de 2020, vive em uma sociedade fria, onde carros futuristas sobrevoam edifícios iluminados pelas luzes de neon de vários outdoors publicitários, onde as expedições a outros planetas já são possíveis, onde se compartilha o mesmo espaço com andróides. O presente do futuro é a vivência da expectativa de ações futuras. Por isso, nele narram-se acontecimentos concomitantes a um marco temporal futuro, estabelecido em relação ao momento da enunciação.

De acordo com Silva (2004), uma narrativa fílmica pode ser contada em três momentos de referência (MR) em favor de um momento de acontecimento (MA): $M R$ presente, MR passado e MR futuro. Ao escolher um destes MR, por conseguinte, os acontecimentos vão sucedendo-se, a partir do presente inicial do presente, do passado e do futuro. Vejamos alguns exemplos:

\section{a) MR presente (MA presente do presente)}

Em As Noites de Cabíria (2002), de Federico Fellini, vemos o desenrolar da vida de Cabíria, uma prostituta que trabalha nas ruas de Roma e que sonha encontrar seu príncipe encantado. Os sonhos de Cabíria são confrontados com as desilusões, os desapontamentos, os desencontros e as amarguras, que vão sucedendo-se em sua vida. Cabíria mora em um lugar afastado da cidade, cercada por gigolôs e outras prostitutas. Desde o início do filme, o seu grande sonho de encontrar um homem que a tirasse da "vida" cai por terra, ou melhor, na água: Cabíria é empurrada, da margem de um rio, por seu então namorado, quase se afogando. A partir desse momento, todos os acontecimentos na vida da prostituta vão sucedendo-se em um desenrolar progressivo e contínuo: conhece um ator, Alberto Lazaro, figura importante nas noites da alta sociedade romana e ilude-se novamente pensando que ele a escolheu como companheira; perde a fé quando vai a uma missa e percebe que ainda não conseguira o marido que desejava; desilude-se mais uma vez com outro homem, Oscar, que promete levá-la embora daquele lugar onde vivia: o tão esperado príncipe rouba todas as economias que ela havia guardado, inclusive o dinheiro da venda de sua casa. Do início ao final do filme, sua vida foi uma sucessão de acontecimentos infelizes, um desenrolar progressivo de grandes amarguras e decepções. Os acontecimentos são temporalizados no presente do presente e a partir daí são narrados numa sucessão.

\section{b) MR passado (MA presente do passado)}

Em Chinatown (2001), de Roman Polansky, na Los Angeles da década de 1930, uma mulher misteriosa contrata os serviços de um detetive particular para vigiar seu marido. A partir daí, uma série de envolvimentos estranhos vai levando o detetive a enfrentar situações cada vez mais intrigantes e bizarras, envolvendo especulação imobiliária, corrupção, incesto e mortes. Há uma progressão contínua dos acontecimentos. As situações desenvolvem-se e há uma constante averiguação, por parte do detetive, dos fatos resultantes e 
assim sucessivamente até o clímax da narrativa. Os acontecimentos são temporalizados no presente do passado e narrados sucessivamente.

\section{c) MR futuro (MA presente do futuro)}

Em A.I. - Inteligência artificial (2002), de Steven Spielberg, em um futuro onde o efeito estufa derreteu as calotas polares e muitas cidades litorâneas, entre elas Nova York, Veneza e Amsterdã, foram inundadas pelos oceanos, David, um menino-andróide criado para desenvolver emoções humanas e dependência afetiva, é ofertado por uma indústria de autômatos a um casal cujo filho está em uma espécie de coma. As feições de David são muito reais e todos crêem ser ele um menino de verdade. David e Mônica, a mãe do menino em coma, desenvolvem uma relação muito forte, como mãe e filho de verdade. Tudo vai indo muito bem até o dia em que o filho de Mônica desperta de seu estado vegetativo. A convivência dos dois meninos desencadeia uma série de ciúmes e malentendidos fazendo Mônica abandonar David em meio a uma floresta sinistra. A partir desse momento, uma série de aventuras leva David a procurar seu verdadeiro objetivo: encontrar a Fada Azul e pedir a ela que o transforme em um menino de verdade, pois só assim teria o amor de Mônica de volta. A aventura de David, dividida claramente em três atos, mostra o processo da busca do menino-andróide para a realização de seu sonho. Em um desenrolar contínuo, vemos as peripécias de David, que tematizam a segregação, o medo da solidão, a busca do amor familiar e maternal e sua aceitação. A sucessão narrativa respeita o desenrolar progressivo dos acontecimentos que envolvem David e o seu sonho de tornar-se um menino de verdade. Os acontecimentos são temporalizados no presente do futuro e os fatos são narrados sucessivamente.

\section{Inversão da ordem dos acontecimentos}

A inversão é a colocação em ordem diferente dos acontecimentos sucessivos. Uma sequência de eventos é narrada do fim para o começo. Dois filmes ilustram bem esse procedimento de programação temporal: Amnésia (2001), de Christopher Nolan, e Irreversível (2001), de Gaspar Noé. Neste filme, a inversão é acionada pelo actante da enunciação; naquele, a inversão é acionada por um actante do enunciado. Vejamos cada caso em particular.

Em Amnésia, um homem perde a memória em decorrência do impacto que sofreu pelo brutal assassinato de sua mulher. Após esse choque, ele só é capaz de se lembrar dos últimos 15 minutos que viveu. Na tentativa de ir atrás dos assassinos de sua esposa, ele tatua em seu corpo os nomes das pessoas que conheceu e os vários locais por onde esteve para não esquecê-los. Seu corpo torna-se uma agenda. A partir daí, a história toda é contada de trás para frente: a solução do crime encontra-se no início, que é o fim da narrativa. Como a memória do homem só é capaz de registrar os últimos 15 minutos, ele começa a reconstituir a história a partir das anotações em seu corpo. A narrativa desenvolve-se então com base nos nomes e nos locais registrados na pele do protagonista. Os acontecimentos vão sendo reconstituídos de acordo com os nomes de pessoas ou de lugares que escolhe ler em seu próprio corpo. Essa mudança da ordem de sucessão dos acontecimentos é regida por um actante do enunciado, o homem com amnésia. O efeito de sentido resultante (a angústia, o desespero) é obra desse sujeito desmemoriado, o protagonista, que produz uma programação temporal não "natural". 


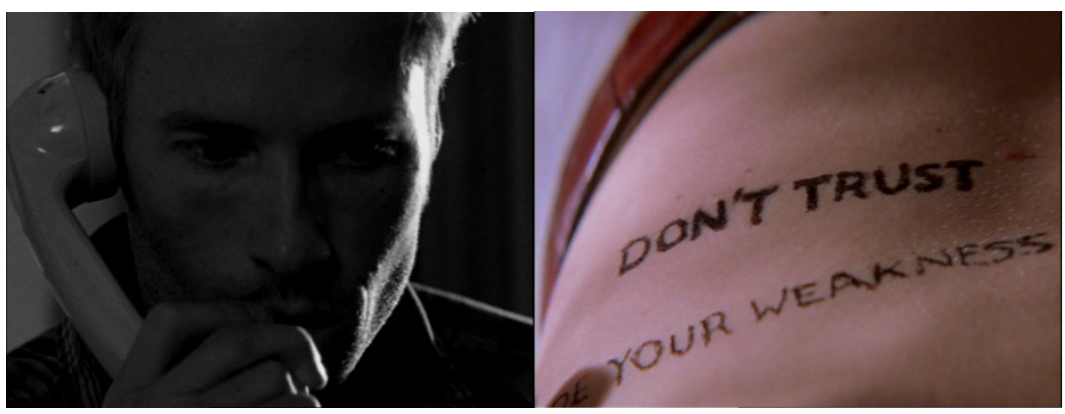

Fotogramas 5 e 6: Em Amnésia, o passado mistura-se ao presente e a ação transcorre de acordo com os nomes tatuados no corpo do protagonista

Em Irreversível, o estupro de uma mulher leva dois homens ao submundo de uma grande cidade francesa. Eles investigam lugares suspeitos, pontos de prostituição e de venda de drogas; entram em bares sadomasoquistas e encontram toda espécie de pessoas envolvidas nesse "novo mundo". Irreversível é o tempo. Como uma espécie de epígrafe, há a seguinte frase no início do filme que narra o epílogo da história: "o tempo destrói tudo". É a partir dessa premissa que o filme ganha o seu desenrolar "inverso". A história é narrada de trás para frente até atingir seu epílogo que é o prólogo do filme, fechando o ciclo: "o tempo destrói tudo". A irreversibilidade do tempo trabalhada nesse filme é um efeito de sentido resultante do ponto de vista de um actante da enunciação, o narrador. O longo retrocesso, que, às vezes, leva a uma sensação nauseante, dado que algumas cenas têm a câmara em espiral, quer transmitir a ideia da irreversibilidade do tempo em sua marcha destrutiva.

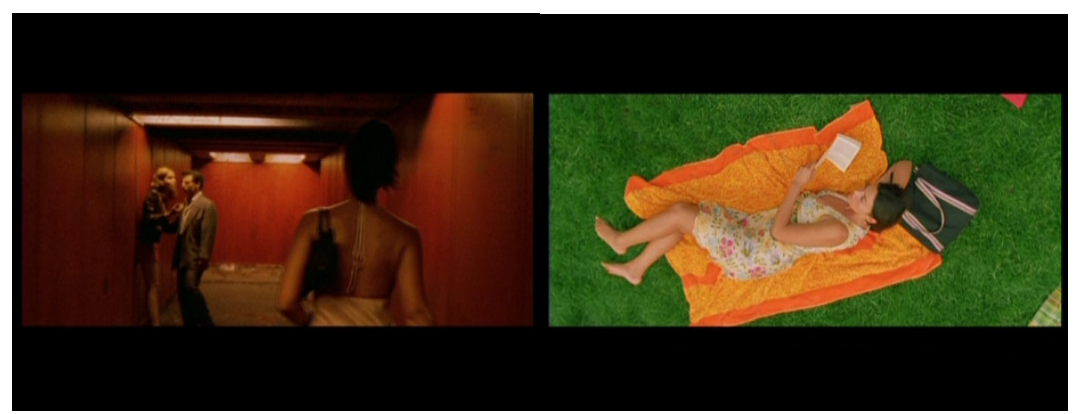

Fotogramas 7 e 8: do momento crítico ao final (começo) id́líico: situações irreversíveis

\section{Conclusão}

Como vimos, a programação temporal é um processo inerente na representação dos fatos fílmicos e merece ser apreciada e englobada pelas teorias da sétima arte. Uma narrativa fílmica, ao utilizar-se dos fundamentos da programação temporal, tem em seu engendramento uma estratégia discursiva muito ampla. Procedimentos como a simultaneização, a sucessão e a inversão dos acontecimentos, dos fatos distintos, ou seja, das ações narrativas, ajudam a criar certos efeitos de sentido que visam a questionar o modo como o espectador recebe o enunciado por meio da categoria temporal. Quando se fala em ritmo alternado e ritmo contínuo, no âmbito da simultaneização das ações narrativas do discurso cinematográfico, tais conceitos, explicitados anteriormente, colocam em pauta, por exemplo, o modo como o enunciador quer transmitir ao espectador, por meio do enunciado, precisamente acionando a categoria temporal, a maneira como vê e compreende os fatos do 
mundo. Tal ideia deve ser pensada como uma estratégia discursiva que o cinema pode apresentar na construção de sua base.

Outro aspecto que foi visto e deve ser salientado diz respeito ao modo como age a inversão da ordem dos acontecimentos. Uma narrativa cinematográfica "contada" de trás para frente suscita diversas possibilidades de efeitos de sentido. No exemplo dos filmes escolhidos aqui, a angústia, o desespero, a náusea, a irreversibilidade do tempo, entre outros, são efeitos de sentido que ajudam a corroborar a ideia de que a inversão da ordem dos acontecimentos, como um dos recursos da programação temporal, também é uma estratégia discursiva em que o enunciador, ao colocá-la em prática, busca enaltecer um aspecto em seu enunciado, quer seja do ponto de vista de um interlocutor, quer seja do ponto de vista do narrador, na esperança de que o espectador ideal compartilhe com ele alguns questionamentos e, sobretudo, essa magnífica capacidade que só cinema tem ao manipular a categoria temporal no cerne de sua linguagem.

Vamos fazer um quadro sinóptico para visualizar as possibilidades de programação temporal, ou seja, a representação da ordem dos acontecimentos no cinema:

\begin{tabular}{|c|c|c|}
\hline \multirow{2}{*}{$\begin{array}{c}\text { Concomitância } \\
\text { (Simultaneizações) }\end{array}$} & Explícita & Implícita \\
\cline { 2 - 3 } & $\begin{array}{c}\text { Progressão em ritmo } \\
\text { contínuo }\end{array}$ & $\begin{array}{c}\text { Progressão em ritmo } \\
\text { alternado }\end{array}$ \\
\hline
\end{tabular}

\begin{tabular}{|l|c|}
\hline \multirow{4}{*}{ Sucessões (posteriorizações) } & MR presente - MA presente do presente \\
\cline { 2 - 2 } & MR passado - MA presente do passado \\
\cline { 2 - 2 } & MR futuro - MA presente do futuro \\
\hline
\end{tabular}

\begin{tabular}{|l|l|}
\hline \multirow{2}{*}{ Inversão da ordem dos acontecimentos } & Inversão acionada por um actante do enunciado \\
\cline { 2 - 2 } & Inversão acionada pelo actante da enunciação \\
\hline
\end{tabular}

Tabela 4: A programação temporal no cinema

Com essa ferramenta em mãos, compreender minuciosamente o engendramento de sentido nas narrativas fílmicas é mais um grande passo nas veredas da interpretação cinematográfica. Portanto, a semiótica se mostra mais uma vez como uma das teorias que deve ser pensada e trabalhada detidamente pelos teóricos da sétima arte, pois, além de oferecer um referencial teórico preciso, a aplicabilidade dessa teoria à análise dos filmes se mostra uma alternativa cada vez mais sólida para se entender todo o processo de engendramento do discurso cinematográfico em todas as suas instâncias. 
CASA, Vol.7 n.2, dezembro de 2009

Ao eterno mestre,

José Luiz Fiorin

\section{Referências Bibliográficas}

AUMONT, Jacques; MARIE, Michel. Dicionário teórico e crítico de cinema. Campinas: Papirus, 2003.

BARROS, Diana Luz Pessoa de. Teoria do discurso - fundamentos semióticos. São Paulo: Atual, 1988.

FIORIN, José Luiz. As astúcias da enunciação - as categorias de pessoa, espaço e tempo. São Paulo: Ática, 1996.

GREIMAS, Algirdas Julien; COURTÉS, Joseph. Dicionário de semiótica. São Paulo: Contexto, 2008.

REIS, Carlos; LOPES, Ana Cristina M. Lopes. Dicionário de teoria narrativa. São Paulo: Ática, 2002.

SILVA, Odair José Moreira da. A manifestação de Cronos em 35 mm - o tempo no cinema. 2004. 230 f. Dissertação de mestrado - Faculdade de Filosofia, Letras e Ciências Humanas, Universidade de São Paulo, São Paulo, 2004.

\section{Referências Filmográficas}

A.I. - INTELIGÊNCIA Artificial = A.I. - Artificial Intelligence. Direção: Steven Spielberg. Produção: Amblin/Stanley Kubrick; Kathleen Kennedy; Bonnie Curtis; Steven Spielberg; Jan Harlan; Walter F. Parkes. Estados Unidos: Warner Bros. Pictures; Dreamworks Pictures, 2001. 1 DVD

AMNÉSIA = Memento. Direção: Christopher Nolan. Produção: Team Todd; Suzanne Todd; Jennifer Todd. Estados Unidos: Newmarket; Summit Entertainment, 2000. 1 DVD.

BLADE Runner - o caçador de andróides = Blade Runner. Direção: Ridley Scott. Produção: Michel Deeley. Los Angeles: Warner Brothers, 2006. 1 DVD.

CHINATOWN. Direção: Roman Polanski. Produção: Robert Evans. Estados Unidos: Long Road Productions; Paramount Pictures, Estados Unidos, 2001. 1 DVD.

DEUS e o diabo na terra do sol. Direção: Glauber Rocha. Produção: Luiz Paulino dos Santos; Luiz Augusto Mendes. Brasil: Versátil, 2006. 1 DVD.

IRREVERSÍ IEL = Irreversible. Direção: Gaspar Noé. Produção: Christophe Rossignon. França, 2001. 1 DVD.

A MÁQUINA do tempo = The Time Machine. Direção: Simon Wells. Produção: Walter Parkes; David Valdes. Estados Unidos: Warner Bros. Pictures; Dreamworks Pictures, 2002. 1 DVD. 
CASA, Vol.7 n.2, dezembro de 2009

MONTY Python em busca do cálice sagrado = Monty Python and the Holy Grail. Direção: Terry Gilliam; Terry Jones. Produção: Mark Forstater. Inglaterra: Python (Monty) Pictures; Michael White, 2002. 1 DVD.

NARC. Direção: Joe Carnahan. Produção: Michelle Grace; Ray Liotta; Diane Nabatoff; Julius R. Nasso. Estados Unidos: Europa Filmes, 2002. 1 DVD.

AS NOITES de Cabíria = Le notti di Cabiria. Direção: Federico Fellini. Produção: Dino De Laurentis. Itália: Paramount Pictures, 2002. 1 DVD.

A PRIMEIRA noite de um homem - The Graduate. Direção: Mike Nichols. Produção: Lawrence Turman. Estados Unidos: Embassy Pictures, 1999. 1 DVD.

O SENHOR dos anéis: a sociedade do anel = The Lord of the Rings: The Fellowship of the Ring. Direção: Peter Jackson. Produção: Barrie M. Osborne; Peter Jackson; Fran Walsh; Tim Sanders. Estados Unidos/Nova Zelândia: New Line Cinema, 2001. 1 DVD.

O SENHOR dos anéis: as duas torres = The Lord of the Rings: The Two Towers. Direção: Peter Jackson. Produção: Barrie M. Osborne; Fran Walsh; Peter Jackson. Estados Unidos/Nova Zelândia: New Line Cinema, 2002. 1 DVD.

O SENHOR dos anéis: o retorno do rei $=$ The Lord of the Rings: The Return of the King. Direção: Peter Jackson. Produção: Barrie M. Osborne; Fran Walsh; Peter Jackson. Estados Unidos/Nova Zelândia: New Line Cinema, 2003. 1 DVD. 